\title{
Analisis Pola Konsumsi Masyarakat Kota Jambi Pada Bulan Ramadhan Mengunakan Pendekatan Smart PLs 3.0
}

\author{
Habriyanto, Muhammad Yasir Nasution, Muhammad Yusuf Harahap \\ Dosen Ekonomi dan Bisnis Islam \\ Universitas Islam Negeri Jambi Sulthan Thaha Saifuddin Jambi \\ Email: habriyanto781@gmail.com
}

\begin{abstract}
This research aims to look at the influence of factors that affect the consumption patterns of the community of the city of Jambi. The approach was conducted using smart analysis pls 3.0 to see lines of influence between formative and reflective variable in variable form the outer model and variable inner model. In this study using the 140 respondents with the outcome variable of influence lines reflective of Psychology factor variable indicator of attitudes, knowledge, perception and motives of the latent variable influence on psychology. While the influence of the outer line model formative factors of religiosity which consists of an indicator variable is unity, cleanliness, simplicity, cleanliness and latent variables affect the mandate factor religiosity and indicator variables for Justice, halal and the principle of generosity, morality has no effect against the latent variable factors of religiosity. Outer formative personal factor model consisting of demographic and situational variables influence on personal factors while variable engagement has no effect. Social factors in the form of structure of outer formative model is an indicator variable reference group, social class and cultural influence on latent from. Latent varibel consumption patterns of the community in the form of outer formative model variable indicator of prices of goods, the level of opinion, tastes, and advertising the products variable latent influence on consumption patterns of society whereas the variable indicator number of families have no effect. In the form of lines of influence of latent variable model of inner factors of influence on latent religiosity variable factors psychology, personal, social and societal consumption patterns of the city of Jambi in Ramadaan. To track social factors against the influential community consumption patterns while the latent variable factors of psychology and latent variable has no effect on personal factors. Determination of the coefficient of variation of the latent variable factors of religiosity was able to explain to the latent variable factors psychology, personal factors, social factors and consumption patterns each of $43.2 \%$, $31.7 \%$ and $42.7 \%$. Determination of the coefficient of the latent variable social factors capable of explaining the variation of the latent variable consumption patterns of the community of the city of Jambi in Ramadaan amounting to $61 \%$. Results perhitugan Q square of a variation in the meaning of diversity 0913 model in the study of $91.3 \%$ and $8.7 \%$ is explained by his side other models outside of this research.
\end{abstract}

Keywords:

Religiosity; Psychology; Personal; Social; Consumption Patterns

\section{PENDAHULUAN}

Puasa merupakan aktivitas pemberhentian konsumsi makan dan minum ketika siang hari di mulai dari terbit fajar hingga terbenam matahari. Kegiatan yang dilakukan untuk melatih hawa nafsu dengan menahan motif konsumsi dan hubungan seksual. Hasil dari latihan berpuasa akan melahirkan sifat kesederhanaan dalam konsumsi, memunculkan sifat-sifat spritual yang terpuji seperti kesabaran, rasa syukur, qona`ah dan sifat yang terpuji lainnya. Sehingga ibadah puasa yang dilakukan dapat membentuk kepribadian beriman dan bertaqwa.

Namun apa yang diharapkan ibadah puasa sebagai pembentuk kepribadian yang bertaqwa tidak bisa terwujud, karena konsep ideal dalam berpuasa tidak dijalankan dengan baik, ketika pada siang harinya mereka menahan lapar dan dahaga, tetapi pada saat waktu diperbolehkan mengkonsumsi mereka melampiaskan secara emosional dengan mengkonsumsi sebanyak-banyaknya ketika berbuka puasa dan pada waktu malam harinya hingga sampai datang waktu sahur. Fenomena ini mengakibatkan tingkat konsumsi pada bulan Ramadhan meningkat secara signifikan. Di mana kelompok orang kaya tidak menurunkan konsumsi, bahkan meningkat pesat. Akibatnya, mendorong kenaikan harga (inflasi) sebagai konsekuensi meningkatnya permintaan. Kelompok yang paling dirugikan adalah orang miskin sehingga mereka tidak mampu membeli kebutuhan mereka sebagai dampak kenaikan harga.

Namun fenomena yang terjadi jauh dari konsep ideal dimana ketika pada bulan Ramadhan konsumsi non primer tidak menurun, bahkan meningkat masyarakat muslim terlihat justru banyak mengunjungi pusat-pusat perbelanjaan dalam rangka mempersiapkan kebutuhan lebaran. Pada saat hampir dekatnya waktu berbuka puasa di mana terlihat sejumlah orang ramai mendatangi tempat penjualan makanan berbuka. Aktivitas keseharian pada saat bulan Ramadhan hanya pada tataran tidak makan dan minum akan tetapi prinsip mereformasi moral dan tingkah laku dengan memperbanyak ibadah justru tidak terlihat manakala di pengujung bulan Ramadhan jumlah jemaah semakin berkurang ketika solat di mesjid.

Kondisi di atas juga dukung oleh data survey studi pendahuluan yang dilakukan peneliti dengan wawancarai 50 orang responden. Hasil jawaban menyatakan, konsumsi rumah tangga 
mereka selama bulan Ramadhan mengalami kenaikan masing- masing bervariasi ada menyatakan kenaikan sekitar $10-30 \%$ berjumlah 4 orang, $40-70 \%$ sebanyak 25 orang, $80-100 \%$ berjumlah 10 orang dan $100-150 \%$ sebanyak 6 orang. Kenaikan konsumsi pada bulan Ramadhan meliputi pengeluaran rumah tangga pada saat berbuka puasa, sahur, mempersiapkan kebutuhan pakaian baru, konsumsi pada saat menghadapi lebaran Aidul Fitri dan biaya mudik. (Sumber diolah dari data wawancara, 2018)

Kenaikan konsumsi pada bulan Ramadhan di kota Jambi mengindikasikan aktivitas ibadah puasa yang dilaksanakan tidak memberikan dampak secara spritual dalam mengendalikan dorongan hawa nafsu ketika berhadapan dengan pemenuhan kebutuhan konsumsi rumah tangga. Kondisi ini sangat bertentangan dengan semangat, makna dan filosofis ibadah puasa. Sehingga ibadah puasa yang dijalankan tidak memberikan solusi dalam mengendalikan kenaikan harga dan inflasi.

Fenomena yang terjadi pada masyarakat kota Jambi tentunya ada faktor yang mempengaruhinya, sehingga kondisi permintaan meningkat. Faktor yang mempengaruhi tersebut bisa dilihat dari faktor kepribadian, psikologi, sosial, religiusitas, harga, selera, pendapatan, iklan dan jumlah keluarga konsumen. Pengaruh yang terjadi dapat dijadikan sebuah temuan dan menjadi referensi untuk melihat kondisi dan aktivitas pola konsumsi yang dilakukan pada bulan Ramadhan.

Para ahli berpendapat mengenai defenisi perilaku konsumen, menurut Gerald Zaldman dan Melanie Wallendorf Perilaku konsumen adalah tindakan-tindakan, proses, dan hubungan sosial yang dilakukan individu, kelompok, dan organisasi dalam mendapatkan, menggunakan suatu produk atau lainnya sebagai suatu akibat dari pengalamannya dengan produk, pelayanan, dan sumber-sumber lainya. (Rinidwiastuti,2008:18)

Sedangkan menurut Hawkins, Best, dan Coney Perilaku konsumen adalah studi mengenai individu, kelompok atau organisasi dan proses dimana mereka menyeleksi, menggunakan dan membuang produk, layanan, pengalaman atau ide untuk memuaskan kebutuhan dan dampak dari proses tersebut pada konsumen dan masyarakat. (Rinidwiastuti,2008:18)

Schiffman dan Kanuk mendefenisikan perilaku konsumen sebagai perilaku yang diperlihatkan konsumen dalam mencari, membeli, menggunakan, mengevaluasi dan menghabiskan produk dan jasa yang mereka harapkan akan memuaskan kebutuhan mereka. Menurut Winardi perilaku konsumen adalah perilaku yang ditujukan oleh orang-orang dalam merencanakan, membeli dan menggunakan barang-barang ekonomi dan jasa. (Schiffman dan Kanuk, 2008)

Menurut Solomon Studi Perilaku Konsumen merupakan proses ketika individu atau kelompok menyeleksi, membeli, menggunakan atau membuang produk, pelayanan, ide dan pengalaman untuk memuaskan kebutuhannya.

(Rinidwiastuti,2008:18)

Dari beberapa pendapat dari para ahli di atas dapat disimpulkan bahwa perilaku konsumen adalah sifat atau perilaku individu atau kelompok yang berkaitan dengan pemenuhan kebutuhan dengan cara membeli, menggunakan jasa dalam rangka pemenuhan tingkat kepuasan.

Syariat Islam memiliki seperangkat etika dan norma dalam konsumsi Islami yang bersumber pada Al-Quran dan As-Sunnah. Beberapa etika ini, antara lain keadilan, kebersihan, kesederhanaan, halalan tayyibah, dan kesimbangan. (Anita Rahmawati, 2011:78-79). Menurut Yusuf Qardhawi, ada tiga landasan Norma konsumsi, yaitu:

1. Sederhana dalam mengkonsumsi suatu barang

2. Tidak boros

3. Membelanjakan harta untuk kebaikan. (Anita Rahmawati, 2011:78-79)

Menurut Naqvi, etika Islam dalam hal konsumsi dikelompokan kedalam empat aksioma pokok yaitu: tauhid, keadilan, kebebasan berkehendak dan pertanggungjawaban. (Sayeb Nawab Haidar Naqfi, 1985:78-79). Dengan paparan sebagai berikut:

1. Tauhid

Dalam perpektif Islam, kegiatan konsumsi dilakukan dalam rangka beribadah kepada Allah SWT. Sehingga senantiasa berada dalam hukum-hukum Allah SWT (Syariat). Oleh karena itu orang mukimin berusaha mencari kenikmatan dengan mentaati perintah-perintah-Nya dan memuaskan dirinya dengan barang-barang dan anugrah-anugrah yang diciptakan Allah untuk umat manusia.(Nur Rianto, 2005:188)

Dimensi spritunal yang dimaksud dengan prinsip tauhid adalah bahwa segala aktivitas yang dilakukan adalah bermuara kepada penghambaan diri kepada Allah sebagai pencipta dan sebagai makhluk yang diciptakan tentunya ada maksud dan tujuan kenapa manusia diciptakan. Penciptaan manusia dan segala aktivitasnya maksudnya adalah dalam rangka menjadikan manusia itu tetap mendekatkan diri kepada Allah dengan mengerjakan segala perintahnya dan menjauhi segala perbuatan yang dilarangnya dan segala aktivitas yang tidak mengarah 
kepada pengabdian terhadap sang khalik maka ia tidak bisa dikatakan sebagai ibadah, karena seorang hamba adalah seorang yang selalu taat kepada perintah tuhannya.

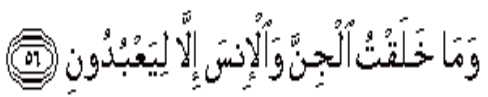

Artinya :

Dan aku tidak menciptakan jin dan manusia melainkan supaya mereka mengabdi kepada-Ku. (QS. Az- Zariyat, 51: 56)

Inti sari dari segala aktivitas khususnya dalam kegiatan ekonomi harus menjadikan kepercayaan sebagai dasar dalam mengambil setiap kebijakan. Dasar pengambilan kebijakan harus sesuai dengan arahan dan tuntunan yang sudah digariskan oleh Allah SWT dalam AI-Quran dan As-Sunnah.

2. Adil (Equilibrium/ keadilan)

Islam memperbolehkan manusia menikmati berbagai karunia kehidupan dunia yang disediakan Allah sebagaimana yang disebutkan dalam ayat:

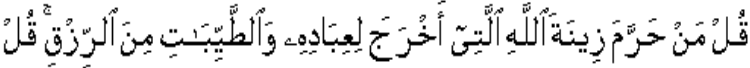

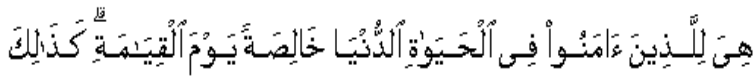

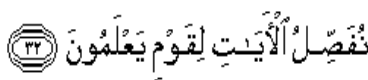

Artinya :

Katakanlah: "Siapakah yang mengharamkan perhiasan dari Allah yang telah dikeluarkan-Nya untuk hamba-hamba-Nya dan (siapa pulakah yang mengharamkan) rezki yang baik?" Katakanlah: "Semuanya itu (disediakan) bagi orang-orang yang beriman dalam kehidupan dunia, khusus (untuk mereka saja) di hari kiamat ${ }^{[536]}$." Demikianlah Kami menjelaskan ayat-ayat itu bagi orang-orang yang mengetahui. (QS. Al-A`raf, 7:32)

Akan tetapi, pemanfaatan atas karunia Allah tersebut harus dilakukan secara adil sesuai dengan syariat sehingga selain mendapatkan keuntungan material, ia juga merasakan kepuasan spritual. Al-Quran secara tegas menekankan norma perilaku ini, baik hal yang bersifat material maupun spritual untuk menjamin adanya kehidupan yang berimbang antara kehidupan dunia dan kehidupan akhirat. Oleh karena itu, dalam Islam konsumsi tidak hanya barang-barang yang sifat duniawi, tetapi juga untuk kepentingan di jalan Allah SWT. (Nur Rianto, 2005:191)

3. Free Wiil (Kehendak Bebas)
Alam semesta adalah milik Allah SWT, yang memiliki kemahakuasaan (kedaulatan) sepenuhnya dan kesempurnaan atas mahluk-mahluk-Nya. Manusia diberi kekuasaan untuk mengambil keuntungan dan manfaat sebanyak-banyaknya sesuai dengan kemampuaannya atas barang-barang ciptaan Allah SWT. Atas segala karunia yang diberikan oleh Allah SWT., manusia dapat berkehendak bebas, tetapi kebebasan ini tidak berarti bahwa manusia terlepas dari qadha dan qadar yang merupakan hukum sebab akibat yang didasari oleh pengetahuan dan kehendak Allah SWT. Kebebasan dalam melakukan aktivitas harus tetap memiliki batasan agar tidak menzalimi pihak lain. Hal inilah yang tidak terdapat dalam ekonomi konvensional, sehingga yang terjadi kebebasan yang dapat mengakibatkan pihak lain menderita. .(Nur Rianto, 2005:192)

4. Amanah

$$
\text { Pertanggungjawaban) }
$$

Manusia adalah khalifah atau pengembang amanah Allah SWT. Manusia diberi kekuasaan untuk melaksanakan tugas khalifah ini dan untuk mengambil keuntungan dan manfaat sebanyak-banyaknya atas ciptaan Allah SWT. Dalam hal melakukan konsumsi, manusia dapat berkehendak bebas, tetapi ia harus mempertanggungjawabkan atas kebebasan tersebut, baik terhadap keseimbangan alam, masyarakat, diri sendiri, maupun diakhirat kelak. Pertanggungjawaban sebagai seorang muslim bukan hanya kepada Allah SWT, melainkan juga pada lingkungan. Jika ekonomi konvensional, baru mengenal istilah corporate social responsbility, ekonomi Islam telah mengenalnya sejak lama. (Nur Rianto, 2005:192)

5. Halal

Halal adalah syarat yang mutlak dalam kegiatan konsumsi terhadap berbagai barang-barang agar mutu dan kualitas barang tetap terjaga baik secara kebendaan maupun bagaimana cara proses mendapatkannya. Dalam kerangka acuan Islam, barang-barang yang dapat dikonsumsi hanyalah barang-barang yang dapat menunjukan nilai-nilai kebaikan, kesucian, keindahan dan menimbulkan kemaslahatan untuk umat, baik secara material maupun spritual. Benda yang najis, tidak bernilai, tidak dapat digunakan dan tidak dapat dianggap sebagai barang-barang konsumsi dalam Islam yang dapat menimbulkan kemudharatan apabila dikonsumsi akan dilarang. 


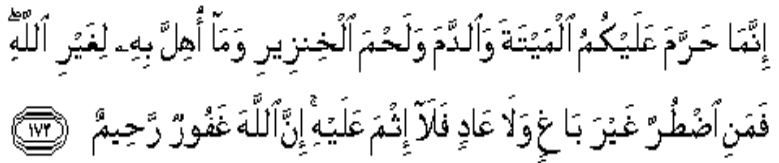

Artinya :

Sesungguhnya Allah hanya mengharamkan bagimu bangkai, darah, daging babi, dan binatang yang (ketika disembelih) disebut (nama) selain Allah ${ }^{[108]}$. Tetapi barangsiapa dalam keadaan terpaksa (memakannya) sedang dia tidak menginginkannya dan tidak (pula) melampaui batas, maka tidak ada dosa baginya. Sesungguhnya Allah Maha Pengampun lagi Maha Penyayang. (QS. Al-Baqarah, 2: 73)

\section{Sederhana}

Islam sangat melarang perbuatan yang melampaui batas (israf), termasuk pemborosan dan berlebih-lebihan (bermegah-megahan) yaitu membuang harta dan menghambur-hamburkannya tanpa faedah serta manfaat dan hanya memperturutkan hawa nafsu. Allah SWT sangat mengecam setiap perbuatan yang lampaui batas. .(Nur Rianto, 2005:193)

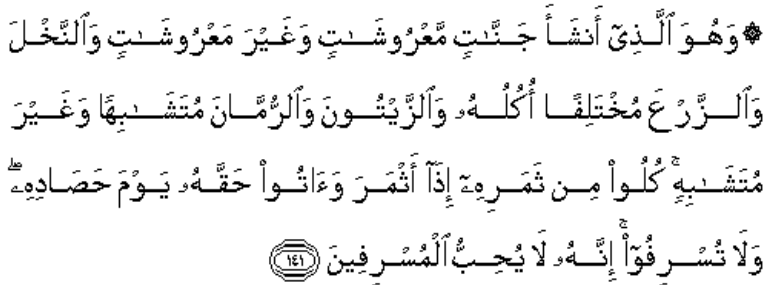

Artinya:

Dan Dialah yang menjadikan kebun-kebun yang berjunjung dan yang tidak berjunjung, pohon korma, tanam-tanaman yang bermacam-macam buahnya, zaitun dan delima yang serupa (bentuk dan warnanya) dan tidak sama (rasanya). Makanlah dari buahnya (yang bermacam-macam itu) bila dia berbuah, dan tunaikanlah haknya di hari memetik hasilnya (dengan disedekahkan kepada fakir miskin); dan janganlah kamu berlebih-lebihan. Sesungguhnya Allah tidak menyukai orang yang berlebih-lebihan. (QS. Al-An`am, 6: 141)

Sedangkan menurut Kahf (1995:195) sasaran konsumsi bagi konsumen muslim adalah sebagai berikut:

1. Konsumsi untuk diri sendiri dan keluarga

2. Tabungan

3. Konsumsi sebagai tanggungjawab sosial

Menurut M.A Mannan ada lima prinsip dasar yang mengendalikan kegiatan konsumsi agar sesuai dengan etika Islam, yaitu:
1. Prinsip keadilan.

2. Prinsip kebersihan.

3. Prinsip kesederhanaan.

4. Prinsip kemurahan hati.

5. Prinsip moralita (Abdul Mannan,1993:45)

Menurut Pride dan Ferrel, membagi faktor yang mempengaruhi perilaku konsumen ke dalam tiga kelompok, (Sangaji, 2013:335-337) yaitu:

1. Faktor Pribadi

Faktor kepribadian dapat didefeniskan sebagai suatu bentuk dari sifat-sifat yang ada pada diri individu yang sangat menentukan perilakunya.(Anwar Mangkubumi, 2009:46). Faktor pribadi merupakan faktor yang unik bagi seseorang, berbagai faktor pribadi dapat mempengaruhi keputusan pembelian. Faktor pribadi digolongkan menjadi tiga, yaitu:

a. Faktor Demografi

Faktor demografi berkaitan dengan siapa yang terlibat dalam pengambilan keputusan pembelian. Faktor ini meliputi ciri-ciri individual seperti jenis kelamin, usia, ras, suku bangsa, pendapatan, siklus, kehidupan keluarga dan pekerjaan.

b. Faktor Situasional

Faktor situasional merupakan keadaan atau kondisi eksternal yang ada ketika konsumen membuat keputusan pembelian.

c. Faktor Keterlibatan

Faktor tingkat keterlibatan konsumen ditunjukan dengan sejauh mana konsumen mempertimbangkan terlebih dahulu keputusannya sebelum membeli sebuah produk.

2. Faktor Psikologi

Faktor psikologi yang ada pada diri seseorang sebagian menetapkan perilaku orang tersebut sehingga mempengaruhi perilakunya sebagai konsumen. Faktor-faktor psikologi meliputi:

a. Motif

Motif adalah kekuatan energi internal yang mengarahkan kegiatan seseorang ke arah pemenuhan kebutuhan atau pencapaian sasaran. .(Anwar Mangkubumi, 2009:46). Sedangkan pengertian motif menurut Bambang Samsul Arifin, motif adalah merupakan sesuatu yang melingkupi semua penggerak, alasan atau dorongan, keinginan, hasrat dan tenaga penggerak lainnya yang berasal dari dalam dirinya untuk melakukan sesuatu. Motif-motif itu memberikan tujuan dan arah pada tingkah laku manusia dan kegiatan-kegiatan yang dilakukan sehari-hari juga mempunyai motif tersendiri. Motif-motif manusia dapat bekerja secara sadar dan tidak sadar bagi diri manusia.(Bambang, 2005:143). 
Menurut Gerungan mendefenisikan motif sebagai suatu pengertian yang melengkapi semua penggerak alasan atau dorongan-dorongan dalam diri manusia yang menyebabkan dia berbuat sesuatu. Dengan pengertian bahwa semua tingkah laku manusia mempunyai motif.(WA.Gerung, 2010:151)

b. Persepsi

1) Pengertian Persepsi

Secara etimologi, persepsi berasal dari bahasa latin. Perceptio yang berarti menerima atau mengambil. Persepsi adalah proses pemilihan, pengorganisasian dan penginterpretasian masukan informasi untuk menghasilkan makna. Kemudian persepsi dapat di defenisikan sebagai proses pengorganisasian dan memaknakan kesan-kesan indra untuk memberikan arti terhadap lingkungannya. Seseorang mempersepsikan terhadap sesuatu dapat berbeda dengan kenyataan yang objektif.(Yuniarti, $2016: 110)$

2) Proses Persepsi

Proses persepsi terjadi melalui tahapan yaitu: 1). Proses fisis, objek yang menimbulkan stimulus dan stumulus mengenai alat indra. 2). Proses fisiologis, stimulus yang diterima alat indra dilanjutkan oleh saraf sensoris ke otak. 3). Proses psikologi, terjadi proses pengolahan otak, sehingga individu menyadari yang ia terima dengan alat indra sebagai akibat dari stimulus yang diterima. .(Yuniarti, $2016: 111)$

3) Persepsi konsumen

Persepsi konsumen adalah proses seorang konsumen untuk mengorganisasikan dan mengartikan kesan dari pancaindra dalam tujuan untuk memberi arti dalam lingkungan mereka.(Stephen,2002)

c. Kemampuan dan pengetahuan

Kemampuan adalah kesanggupan dan efisiensi untuk melakukan tugas-tugas tertentu. Kemampuan yang diminati oleh pemasar adalah kemampuan seseorang individu untuk belajar di mana proses pembelajaran tersebut merupakan perubahan perilaku seseorang yang disebabkan oleh informasi dan pengalaman.

d. Sikap

Sikap merujuk pada pengetahuan dan perasaan positif atau negatif terhadap sebuah objek atau kegiatan tertentu.

e. Kepribadian
Kepribadian adalah semua ciri internal dan perilaku yang membuat seseorang itu unik. Kepribadian seseorang berasal dari keturunan dan pengalaman pribadi.

\section{Faktor Sosial}

Manusia hidup di tengah-tengah masyarakat. Sudah tentu manusia akan dipengaruhi oleh masyarakat di mana dia hidup. Dengan demikian, perilaku konsumen juga akan dipengaruhi oleh masyarakat atau faktor sosial yang melingkarinya. Faktor sosial meliputi

a. Peran dan pengaruh keluarga

b. Kelompok referensi

c. Kelas sosial

d. Budaya dan sub budaya

Terdapat beberapa faktor yang mempengaruhi permintaan barang, yaitu:

1. Harga Barang itu Sendiri

2. Harga Barang Lain yang Terkait

3. Tingkat Pendapatan Per kapita

4. Selera atau Kebiasaan.

5. Jumlah Penduduk

6. Perkiraan Harga di Masa Mendatang.

7. Distribusi Pendapatan.

8. Usaha-usaha Produsen Meningkatkan Penjualan.( Prathama, 2008:25-26)

\section{METODE PENELITIAN}

Penelitian ini mengunakan pendekatan penelitian kuantitatif dengan memakai Smart PLs 3.0 sebagai alat analisis. Teknik pengumpulan data menggunakan angket dengan memakai skala likerts sebagi alat ukur variabel dalam struktur model. Penentuan sampel dalam penelitian menggunakan teknik random sampling yang menganggap semua responden dianggap sama dalam hak menjawab instrumen data. Jumlah sampel ditentukan berdasarkan hasil perkalian terhadap 28 jumlah variabel yang terdiri dari variabel indikator dan laten variabel dengan dikalikan skor 5 menghasilkan 140 jumlah responden. Penentuan sampel bersifat insidental artinya penentuan sampel berdasarkan responden yang bertemu dengan peneliti dilapangan.

\section{HASIL DAN PEMBAHASAN}

\section{Evaluasi alat pengumpulan data (outer model)}

1. Convergent Validity

\section{a. Loading Factor}

Suatu indikator dianggap memenuhi persyaratan convergent validity dalam kategori baik apabila nilai outer loading > 0.70 untuk setiap variabel. Namun menurut Al-Ghazali pada riset tahap pengembangan skala, loading 0,50 sampai 0,60 masih dapat diterima. 
Tabel 2. Nilai Average Variance Extraced (AVE)

Tabel 1. Outer Loading

\begin{tabular}{ccc}
\hline Variabel & Indikator & Outer Loading \\
\hline Faktor Psikologi & X9 & 0.698 \\
& X10 & 0.585 \\
& X11 & 0.862 \\
X12 & 0.867 \\
\hline
\end{tabular}

Berdasarkan tabel 1 di atas nilai outer loading secara keseluruhan berada dalam posisi lebih besar dari 0,5 maka indikator faktor psikologi sudah dianggap valid dan layak untuk dianalisis tahap selanjutnya.

b. Average Variance Extraced (AVE)

Uji lain untuk menilai validitas dari konstruk dengan melihat nilai AVE, dipersyaratkan model yang baik jika AVE masing-masing konstruk nilainya lebih besar dari 0,50.

\begin{tabular}{lc}
\hline & Average Variance Extracted (AVE) \\
\hline \hline Faktor Psikologi & 0.581 \\
\hline
\end{tabular}

Hasil output di atas menunjukan bahwa nilai AVE $0,581>0,50$. Artinya data dari indikator faktor psikologi memenuhi persyaratan uji covegent validity dan bisa digunakan untuk data analisis selanjutnya.

\section{c. Uji Validitas Discriminant}

Discriminant validity indikator reflektif dapat dilihat cross loading antara indikator dengan konstruknya dengan cara pada PLS Algorithm report pilih discriminant validity lalu cross loading berikut ini output smart PLS. .(Imam Ghazali,2015:38)

Tabel 3. Cross Loading

\begin{tabular}{cccccc}
\hline & Faktor Pribadi & Faktor Psikologi & Faktor Religiusitas & Faktor Sosial & $\begin{array}{c}\text { Pola Konsumsi } \\
\text { pada Bulan } \\
\text { Ramadhan }\end{array}$ \\
\hline X9 & 0.442 & 0.698 & 0.298 & 0.508 & 0.362 \\
X10 & 0.387 & 0.585 & 0.178 & 0.391 & 0.278 \\
X11 & 0.613 & 0.862 & 0.736 & 0.686 & 0.623 \\
X12 & 0.674 & 0.867 & 0.544 & 0.681 & 0.598 \\
\hline
\end{tabular}

Berdasarkan hasil dari tabel di atas terlihat bahwa korelasi konstruk faktor psikologi dan indikatornya X9 sikap, X10 pengetahuan, $\mathrm{X} 11$ persepsi dan $\mathrm{X} 12$ motif jika dibandingkan dengan konstruk lainnya seperti faktor pribadi, Religiusitas, Sosial dan pola konsumsi pada bulan Ramadhan lebih tinggi. Hal ini juga berlaku sebaliknya berdasarkan kontruknya masing-masing akan lebih tinggi dibandingkan dengan konstruk lainnya. Hasil tersebut menunjukan bahwa kontruk laten memprediksi indikator pada blok mereka lebih baik jika dibandingkan dengan indikator blok lain.

\section{Uji Reliabilitas}

Setelah melakukan pengujian validitas konstruk, maka selanjutnya diadakan pengujian reliabilitas konstruk dengan diukur berdasarkan uji composite reliability dan cronbach Alpha dari blok indikator yang mengukur konstruk. Indikator yang menjadi konstruk dinyatakan reliabel jika nilai composite reliability dan cronbach Alpha lebih besar dari 0,70 . Uji reliabilitas menggunakan PLS Algorithm dengan memilih hasil composite reliabilty dan cronbach alpha dalam bentuk matrix dan diagram sebagai berikut :

\section{a. Composite Reliability}

Tabel 4. Composite Reliability

\begin{tabular}{cc}
\hline & Composite Reliability \\
\hline \hline Faktor Psikologi & 0.844 \\
\hline \hline
\end{tabular}

Hasil pengujian yang dilakukan nilai skor composite reliability sebesar 0,844 dan jika dibandingkan dengan batas nilai skor reabilitas 0,70 maka, hasil nilai skor composite reliability lebih besar. Besarnya skor yang dihasilkan mengindikasikan bahwa data konstruk dinyatakan reliabel.

\section{b. Cronbach`s Alpha}

Tabel 5. Cronbach's Alpha

\begin{tabular}{cc}
\hline & Cronbach's Alpha \\
\hline \hline Faktor Psikologi & 0.775 \\
\hline
\end{tabular}

Output di atas menghasilkan cronbach alpha sebesar 0,775 dan bila dikofirmasikan dengan batas skor reliabilitas ternyata cronbach alpha $>$ dari 0,70 . Kondisi data yang dihasilkan dapat disimpulkan bahwa konstruk variabel faktor psikologi dinyatakan realibel dan data angket dari responden mengenai faktor psikologi konsumen data digunakan.

\section{Evaluasi Model Pengukuran (Outer Weight) Indikator Formatif}

Pengujian terhadap konstruk indikator formatif menghasilkan hubungan regresi yang dievaluasi menggunakan data outer modelnya dengan melihat nilai relative weight-nya dan nilai 
signifikansi T Statistics. Jika nilai T statistics lebih besar dari 1.96 maka indikator formatif tersebut dianggap valid dan layak untuk dijadikan alat pengukuran konstruk. Kemudian jika skor yang dihasil oleh T Statistisc lebih kecil dari 1.96 maka data yang dihasilkan tidak valid dan tidak memenuhi persyaratan pengujian outer model. Hasil pengujian outer weight dapat dilihat pada tabel berikut ini :

Gambar 1

Outer Model Faktor Yang Mempengaruhi Pola Konsumsi Masyarakat Kota Jambi Pada Bulan Ramadhan

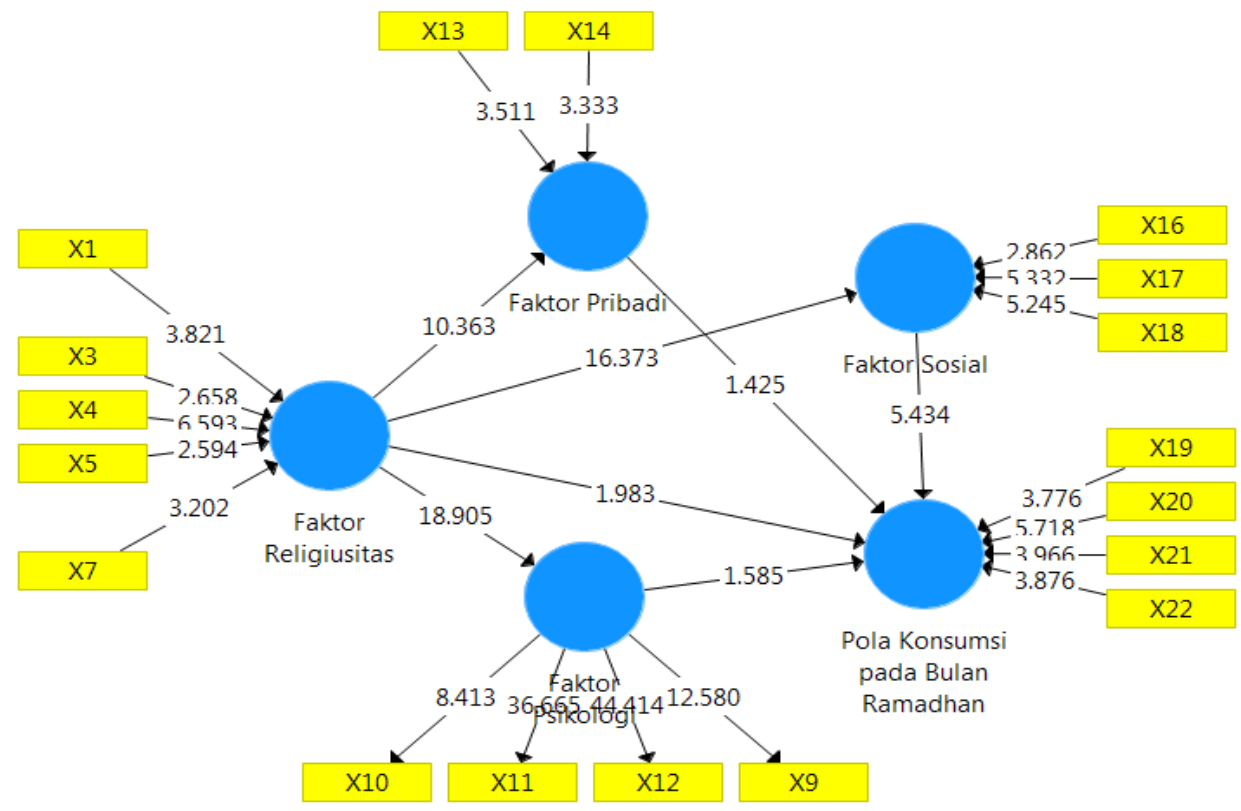

Berdasarkan hasil output di atas nilai $\mathrm{T}$ statistics secara keseluruhan untuk outer model formatif lebih besar dari 1.96 dengan taraf signifikasi lebih kecil dari 0.05. Maka dapat disimpulkan bahwa seluruh data konstruk indikator ke laten variabel formatif dianggap valid dan bisa dijadikan alat pengukuran data masing-masing indikator.

\section{Evaluasi Analisis Jalur Koefisien (Inner Model)}

1. Path Koefisien
Uji path koefisien adalah uji yang digunakan untuk melihat efek hubungan dan pengaruh antara setiap laten variabel eksogen dengan laten variabel endogen. Pengaruh dari masing-masing variabel akan menentukan bentuk koefisien determinasi setelah dibuktikan dengan adanya hubungan dan pengaruh dalam jalur model. Berikut ini akan dijelaskan secara umum hasil uji yang menunjukan hubungan dan pengaruh antara variabel eksogen dan endogon dalam bingkai laten variabel pada tabel dibawah ini.

Tabel 7. Path Koefisien

\begin{tabular}{|c|c|c|c|c|c|}
\hline & $\begin{array}{l}\text { Original } \\
\text { Sample (O) }\end{array}$ & $\begin{array}{l}\text { Sample } \\
\text { Mean (M) }\end{array}$ & $\begin{array}{l}\text { Standard } \\
\text { Deviation } \\
\text { (STDEV) }\end{array}$ & $\begin{array}{l}\text { TStatistics } \\
(|\mathrm{O} / \mathrm{STDEV}|)\end{array}$ & P Values \\
\hline Faktor Religiusitas -> Faktor Pribadi & 0.563 & 0.572 & 0.054 & 10.363 & 0.000 \\
\hline Faktor Religiusitas -> Faktor Psikologi & 0.657 & 0.665 & 0.035 & 18.905 & 0.000 \\
\hline Faktor Religiusitas -> Faktor Sosial & 0.654 & 0.663 & 0.040 & 16.373 & 0.000 \\
\hline $\begin{array}{c}\text { Faktor Religiusitas -> Pola Konsumsi pada Bulan } \\
\text { Ramadhan }\end{array}$ & 0.164 & 0.155 & 0.082 & 1.983 & 0.049 \\
\hline $\begin{array}{c}\text { Faktor Pribadi -> Pola Konsumsi pada Bulan } \\
\text { Ramadhan }\end{array}$ & -0.134 & -0.121 & 0.094 & 1.425 & 0.156 \\
\hline $\begin{array}{c}\text { Faktor Psikologi -> Pola Konsumsi pada Bulan } \\
\text { Ramadhan }\end{array}$ & 0.177 & 0.176 & 0.112 & 1.585 & 0.115 \\
\hline $\begin{array}{c}\text { Faktor Sosial }->\text { Pola Konsumsi pada Bulan } \\
\text { Ramadhan }\end{array}$ & 0.608 & 0.617 & 0.112 & 5.434 & 0.000 \\
\hline
\end{tabular}

Berdasarkan hasil data di atas uji path koefisien antara variabel laten faktor religiusitas dengan laten variabel Faktor Pribadi berpengaruh karena nilai T Statistik 
yang dihasilkan sebesar 10.363> 1.96 dan dilihat dari hasil $P$ value sebesar $0.000<0.05$. Kemudian untuk uji path koefisien faktor religiusitas dengan faktor sosial menghasilkan nilai skor T statistik sebesar $18.905>1.96$ dengan $P$ value $0.000>0.05$. Jika hasil $T$ statistik lebih besar dari nilai signifikansi 1.96 dan lebih kecil dari 0.05 maka dapat dinyatakan mempunyai pengaruh. Path koefisien antara laten variabel faktor religiusitas dengan faktor sosial menghasilkan nilai skor T statistik sebesar $16.373>1.96$ dengan hasil taraf signifikansi sebesar 0.000 $<0.05$ dan dinyatakan berpengaruh. Hasil pengujian path koefisien antara laten variabel faktor religiusitas dengan pola konsumsi masyarakat kota Jambi pada bulan Ramadhan terdapat pengaruh dengan hasil skor nilai $\mathrm{T}$ statistik sebesar $1.983>1.96$ dan taraf signifikansi $0.049<0.05$.

Uji path koefisien antara variabel laten faktor pribadi dengan laten variabel pola konsumsi pada bulan Ramadhan tidak berpengaruh karena nilai $T$ Statistik yang dihasilkan sebesar 1,425 $<1.96$ dan dilihat dari hasil $P$ value sebesar $0,156>0.05$. Kemudian untuk uji path koefisien faktor psikologi dengan pola konsumsi masyarakat kota Jambi pada bulan Ramadhan menghasilkan nilai skor $\mathrm{T}$ statistik sebesar $1,585<1.96$ dengan $P$ value $0,115>0.05$. Maka dapat dinyatakan tidak terdapat pengaruh antara laten variabel faktor psikologi dengan pola konsumsi masyarakat kota Jambi pada bulan Ramadhan. Sedangkan untuk uji path koefisien antara laten variabel faktor sosial dengan pola konsumsi masyarakat kota Jambi pada bulan Ramadhan menghasilkan skor $\mathrm{T}$ statistik sebesar $5.434>1.96$ dan hasil signifikansi sebesar $0.000<0.05$. Hasil skor menunjukan terdapat pengaruh antar laten variabel faktor sosial dengan laten variabel pola konsumsi masyarakat kota Jambi pada bulan Ramadhan.

\section{Model Indirect Effects}

Model Indirect Effects mengambarkan hubungan dan pengaruh variabel eksogen dan variabel intervening yang secara tidak langsung berhubungan atau berpengaruh terhadap variabel endogen. Hubungan dan pengaruh yang tidak secara langsung terhadap variabel endogen merupakan bentuk mata rantai dari sebuah model struktural. Dalam tabel berikut ini akan dipaparkan hasil uji Indirect Effects dan bentuk hubungan atau pengaruh antara variabel eksogen, variabel interving dan variabel endogen.

Tabel 8. Indirect Effects

\begin{tabular}{|c|c|c|c|c|c|}
\hline & $\begin{array}{c}\text { Original } \\
\text { Sample }(O)\end{array}$ & $\begin{array}{l}\text { Sample } \\
\text { Mean (M) }\end{array}$ & $\begin{array}{l}\text { Standard } \\
\text { Deviation } \\
\text { (STDEV) }\end{array}$ & $\begin{array}{l}\text { T Statistics } \\
(|\mathrm{O} / \mathrm{STDEV}|)\end{array}$ & P Values \\
\hline $\begin{array}{l}\text { Laten variabel faktor religiusitas -> Pola } \\
\text { Konsumsi pada Bulan Ramadhan }\end{array}$ & 0.446 & 0.470 & 0.063 & 7.128 & 0.000 \\
\hline
\end{tabular}

Berdasarkan data pada tabel di atas terlihat bahwa laten variabel yang secara tidak langsung mempunyai hubungan atau pengaruh terdapat pada laten variabel faktor religiusitas terhadap pola konsumsi masyarakat kota Jambi pada bulan Ramadhan. Hasil Indirect Effects mempunyai pengaruh terhadap variabel endogennya dalam kategori sedang sebesar 0,446 dengan T statistics sebesar $7,128>1.96$ dan taraf signifikansi sebesar $0.0000<0.05$.

3. Koefisien Determinasi $\left(R_{2}\right)$

Evaluasi path coefficient digunakan untuk menunjukkan seberapa kuat efek atau pengaruh variabel independen kepada variabel dependen. Sedangkan coefficient determination ( $R$-Square) digunakan untuk mengukur seberapa banyak variabel endogen dipengaruhi oleh variabel lainnya. Chin menyebutkan hasil R2 sebesar 0.67 ke atas untuk variabel laten endogen dalam model struktural mengindikasikan pengaruh variabel eksogen (yang mempengaruhi) terhadap variabel endogen (yang dipengaruhi) termasuk dalam kategori baik. Sedangkan jika hasilnya sebesar $0.33-0.67$ maka termasuk dalam kategori sedang, dan jika hasilnya sebesar $0.19-0.33$ maka termasuk dalam kategori lemah.(Imam Ghazali,2015:39).

Berdasarkan pengolahan data menggunakan program SmartPLS 3.0 maka hasil uji koefisien determinasi dapat dilihat pada tabel berikut ini. Tabel 9. Koefisien Determinasi $\left(\mathbf{R}_{2}\right)$

\begin{tabular}{cccccc}
\hline & $\begin{array}{c}\text { Original Sample } \\
(\mathrm{O})\end{array}$ & $\begin{array}{c}\text { Sample } \\
\text { Mean (M) }\end{array}$ & $\begin{array}{c}\text { Standard } \\
\text { Deviation } \\
(\text { STDEV) }\end{array}$ & $\begin{array}{c}\text { T Statistics } \\
(\mid \mathrm{O} / \mathrm{STDEV})\end{array}$ & P Values \\
\hline Faktor Pribadi & 0.317 & 0.330 & 0.062 & 5.119 & 0.000 \\
Faktor Psikologi & 0.432 & 0.444 & 0.046 & 9.406 & 0.000 \\
Faktor Sosial & 0.427 & 0.441 & 0.052 & 8.146 & 0.000 \\
Pola Konsumsi pada Bulan Ramadhan & 0.610 & 0.641 & 0.050 & 12.217 & 0.000 \\
\hline
\end{tabular}


4. Preditive Relevan $\left(Q_{2}\right)$

Untuk mengukur preditive relevan $Q_{2}$ dapat menggunakan rumus sebagai berikut.

$\mathrm{Q}_{2}=1-\left(1-\mathrm{R} 1^{2}\right)\left(1-\mathrm{R}^{2}\right)\left(1-\mathrm{R} 3^{2}\right)\left(1-\mathrm{R} 4^{2}\right)$

$\mathrm{Q}_{2}=1-(1-0,317)(1-0,432)(1-0,427)(1-$ $0.610)$

$\mathrm{Q}_{2}=1-(0.683)(0.568)(0.573)(0.390)$

$\mathrm{Q}_{2}=1-0.086694$

$\mathrm{Q}_{2}=0.913$

Berdasarkan hasil perhitungan di atas, nilai Q Square sebesar 0.913. Hal ini menunjukan bahwa besarnya keragaman model dalam penelitian ini sebesar $91.3 \%$. Sedangkan $8.7 \%$ dijelaskan oleh faktor lain yang diluar model dalam penelitian ini. Hasil $Q$ Square ini menunjukan bahwa model dalam penelitian ini telah memiliki goodness of fit yang baik.

5. Goodness of Fit Index (GoF)

Dalam menentukan nilai Goodness of Fit Index (GoF) untuk SEM PLS dalam penelitian ini menggunakan model yang dikembangkan oleh Tenenhaus dengan sebutan GoF index. Index ini dikembangkan untuk mengevaluasi model pengukuran dan model struktural dan disamping itu menyediakan pengukuran sederhana untuk keseluruhan prediksi model. .(Imam Ghazali,2015:81) Untuk alasan ini GoF index di hitung dari akar kuadrat nilai average communality index dan average R-square dengan rumus sebagai berikut :

$$
G o F=\sqrt{\bar{E} A V E} \times R^{2}
$$

Nilai communality yang direkomendasikan $=0.50$ (Fornel dan Larcker 1981,39-50) dan nilai R-square Small $=0.02$, Medium $=0.13$ dan large $=0,26$ ( Cohen 1988). Maka hasil yang diperoleh sebesar 0.675 dengan demikian maka nilai GoF index termasuk dalam kategori besar dan model yang telah dibentuk dalam penelitian ini dianggap baik

\section{SIMPULAN}

Faktor yang mempengaruhi pola konsumsi masyarakat kota Jambi pada bulan Ramadhan secara path koefisien berasal dari faktor sosial yang terdiri dari kelompok referensi, kelas sosial dan kebudayaan. Pola konsumsi juga dipengaruhi oleh tingkat pendapatan, selera dan iklan produk. Sedangkan variasi faktor sosial menerangkan pola konsumsi masyarakat kota Jambi pada bulan Ramadhan sebesar $61 \%$ dan sisanya $39 \%$ dijelaskan oleh faktor diluar penelitian ini. Kemudian variabel indikator tingkat pendapatan mempunyai pengaruh sebesar 0,447 , variabel indikator selera dan kebiasaan sebesar 0,383 dan variabel indikator iklan produk sebesar 0,355 .

Untuk model Indirect Effects antara faktor religuisitas laten variabel eksogen, laten variabel perantara faktor sosial terhadap laten variabel endogen pola konsumsi masyarakat kota Jambi pada bulan Ramadhan sebesar 0,446.

\section{DAFTAR PUSTAKA}

Anonim, Al-Quran, Semarang: CV. Thoha Putra, 1989

Anita Rahmawati, Ekonomi Mikro Islam. Kudus: Nora Media Enterprise, 2011

Abdul Manna, Teori dan Praktek Ekonomi Islam. Yogyakarta: PT. Dana Bakti Wakaf, 1993

Anwar Prabu Mangku Negara, Perilaku Konsumen. Bandung: PT. Refika Aditama, 2009

Bambang, Psikologi Sosial. Bandung: Pustaka Setia, 2015

Fornell. C., and Larcker, D. F, Evaluating Structural Equation Models With Unobservable and Measurement Error, Journal of Marketing Research 1981

Imam Ghazali, Partial Least Sguares Konsep, Teknik dan Aplikasi Menggunakan Program SmartPLS 3.0, Semarang: Universitas Dipenogoro, 2015

Imam Ghozali, Structural Equation Modeling Metode Alternatif dengan Partial Least Squares (PLS), Semarang: Universitas Diponegoro, 2015

Monzer Khaf, Ekonomi Islam (Telaah Analitik Terhadap Fungsi Sistem Ekonomi Islam), Terjemahan Yogyakarta Pustaka Pelajar, 1995

Nugroho J. Setiadi, Perilaku Konsumen. Jakarta: Studi Press, 2003

Nur Rianto, Pengantar Ekonomi Syariah Teorik dan Praktek. Bandung: Pustaka Setia, 2015

Prathama dkk, Pengantar IImu Ekonomi Mikro dan Makro. Lembaga Penerbit Fakultas Ekonomi UI, 2008

Rinidwiastuti dkk, IImu Perilaku Konsumen. Malang: Universitas Brawijaya Press, 2003

Schiffman dan Kanuk, Consumer Behavior. New Jersey: Prentice, 2000

Sayeb Nawab Haidar Naqfi, Etika dan IImu Ekonomi, suatu Sintesis Islami, Bandung: Mizan, 1985

Sangaji, Sopiah, Perilaku Konsumen Pendekatan Praktis.Yogyakarta: C.V. Andi, 2013

Stephen P. Robbins, Prinsip-Prinsip Perilaku Organisasi. Alih Bahasa Halida dan Dewi Sartika, Jakarta: Erlangga, 2002

Winardi, Kamus Ekonomi, Penerbit Mandar Maju, Bandung, 1989

W.A. Gerungan, Psikologi Sosial. Bandung : Refika Aditama, 2010

Yuniarti Sri Vinna, Ekonomi Mikro Syariah. Bandung: Pustaka Setia Bandung, 2016 